\title{
Stiffness and damage in masonry bridges
}

Bill Harvey BSC, PhD, CEng, FICE, FIStructE

Bill Harvey Associates Ltd., Exeter, Devon, UK

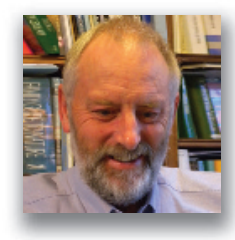

Load-related damage to masonry bridges is relatively uncommon. The author is aware of only a small number of cases and nearly all of them are in structures carrying high railway loads. Current assessment tools do not deliver any indication of the failure mechanisms that actually occur. Those mechanisms are characterised by the progressive development of cracks in various positions. Recent observations have made it clear that: bridges with internal spandrel walls create complex stiffness issues; so-called spandrel cracks and apparent ring separation are different manifestations of the same issue; the construction of some small bridges is not as assumed but often includes internal spandrel walls. This paper describes the damage observed, the construction to which it is related and the mechanisms creating damage. No calculations of any form are offered. This paper merely provides a first step in identifying the cause of a problem and a potential approach to analysis. The discussion begins with stone masonry viaducts, progresses to brick viaducts and concludes with problems in small span bridges.

\section{Introduction}

By far the most common cause of deterioration in masonry bridges is water flowing either through the structure or past it. The second most common cause is vegetation growth, which in turn is often a secondary symptom of the presence of water. Ring separation in brick arches can often be attributed to the after-effects of removing the falsework, when the arch and foundations first come under load. Damage that is directly attributable to live loads is rare indeed. but when it does occur the consequences can be serious.

Harvey and Smith (1991) proposed an approach to multi-span masonry viaducts that was bound by the erroneous concept of an effective width. This has been demonstrated (Harvey, 2006) to be untenable even for single-span bridges. More recent observation of viaducts has suggested an alternative view of behaviour and this must first be explored.
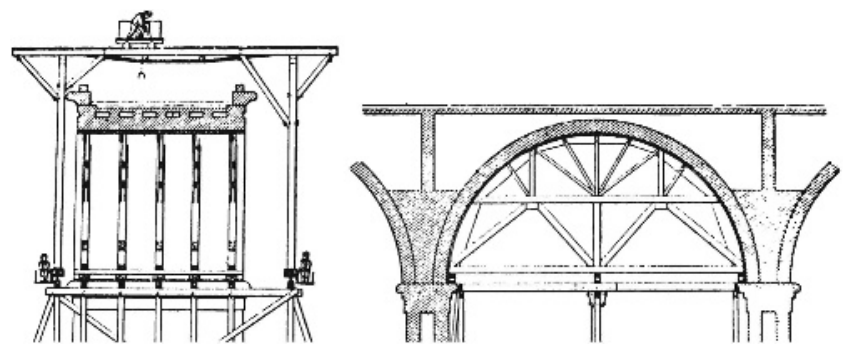

Figure 1. Sections through a typical viaduct showing solid block over pier and hollows above
The construction of typical viaducts is well illustrated by the cross-section of Lugar Viaduct (Figure 1). The arch proper is thickened towards the pier with solid masonry infill. Often, this solid block forms a base for a hollow element, revealed in the cross-section of London Road Viaduct, Brighton (Figure 2).

\section{Behaviour of viaducts: diagnosis}

The vast majority of viaducts are of complex masonry construction. Typically, they will have relatively slender piers supporting a block of solid masonry. Above that will be a series of parallel longitudinal walls with either slabs or jack arches (Figure 2) forming a flat surface, then a small amount of fill below the ballast or surfacing. In 1989 the author proposed that the natural thrust line for any arch after decentring is the minimum thrust, rising from the intrados at

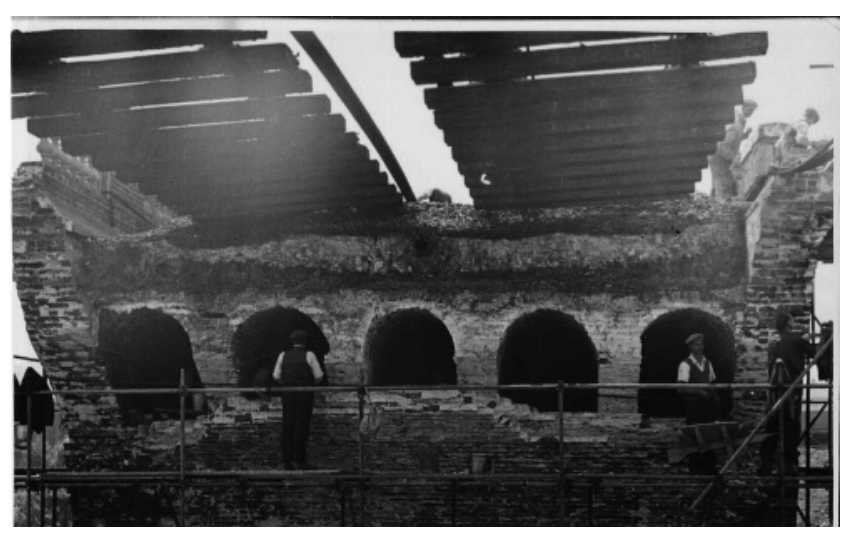

Figure 2. Cross-section of London Road Viaduct, Brighton 
Stiffness and damage in masonry bridges

Harvey the springings to the extrados at mid-span. This thrust pattern is then modified by live loads producing active response in the loaded span and passive response in the unloaded (Figure 3). Active response involves the arch spreading and cracking at three points to form hinges (marked here in span 1 with rings). This generates the minimum possible horizontal thrust. Passive response occurs when the arch is squashed horizontally. In this case the thrust flattens and the horizontal component increases as in span 2 where the thrust has moved away from the rings marking the initial hinge points. Figure 3 shows solid masonry producing a continuous horizontal load path from abutment to abutment. This is typical of most real viaducts, although rarely produced by solid masonry as here.

If the pier is not stiff enough to produce horizontal force, the thrusts must balance further. In Figure 4 rather higher thrusts are in balance in such a way that the load on the pier is eccentric, but vertical. The Archie programme (Harvey and

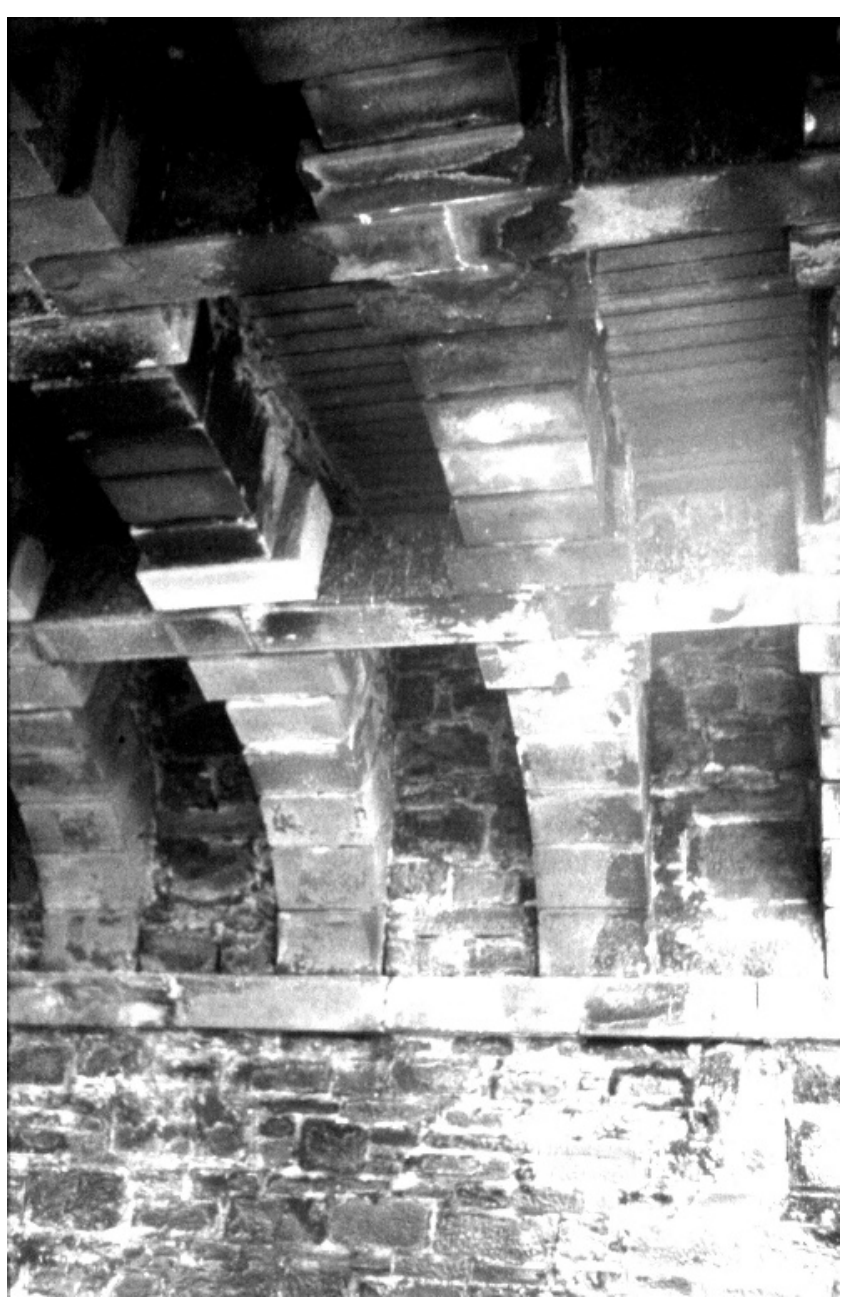

Figure 3. Active/passive response of arches

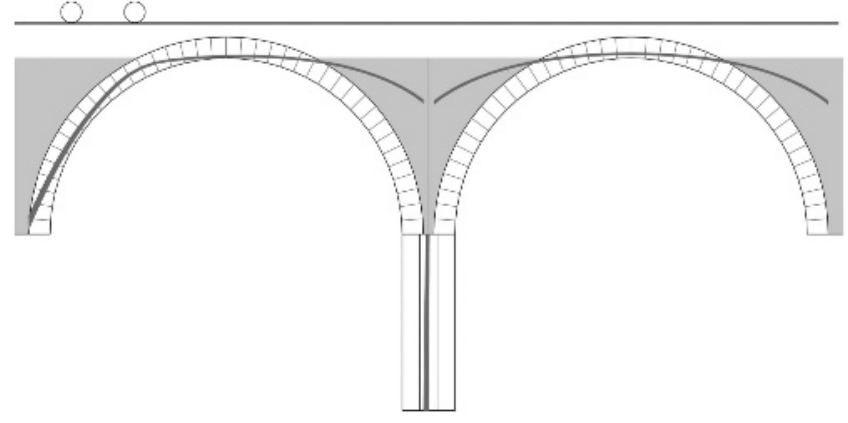

Figure 4. Result of pier top rotation with high thrusts and no outof-balance horizontal force

Juhasz, 2011), from which these figures are taken, maintains equilibrium between the loads in the arch while allowing adjustment of the reactions.

The stresses induced by live loads in the solid block of masonry (mentioned above and highlighted in Figure 5) are unlikely to be sufficient to crack the material in any direction. However, free rocking of the pier section must be resisted if the structure is to stand. The natural effect of a load applied near the middle of the span will be for the adjoining very stiff sections to rotate as rigid bodies. This will ensure that the thrust rises to the top of the arch in the loaded span and moves towards the bottom in the next span. Lines of thrust between these points are of very limited value because the block is essentially a massive continuum in which it is impossible to divide the material into sections that can be treated as independent weights altering the thrust. The programme Archie-M (used to produce Figures 3 and 4) overcomes this problem by treating the masonry block as a dead weight shared between the arch sections below. This view must be recognised as a gross simplification. On the other hand, to trace two thrusts until they meet in a single block as Brunel did for his Maidenhead Bridge (Figure 6) cannot be defended.

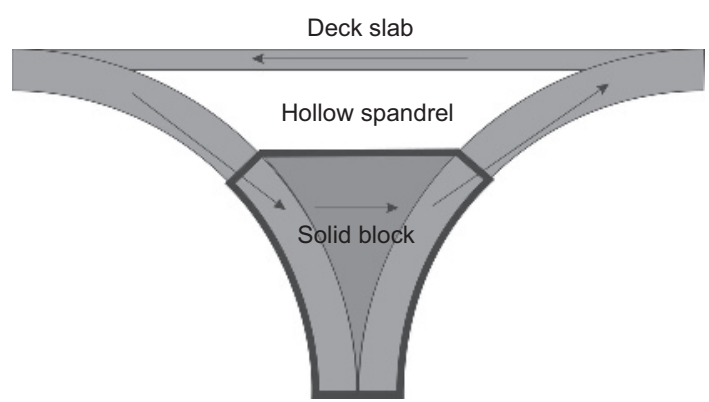

Figure 5. Torsion box round spandrel void 


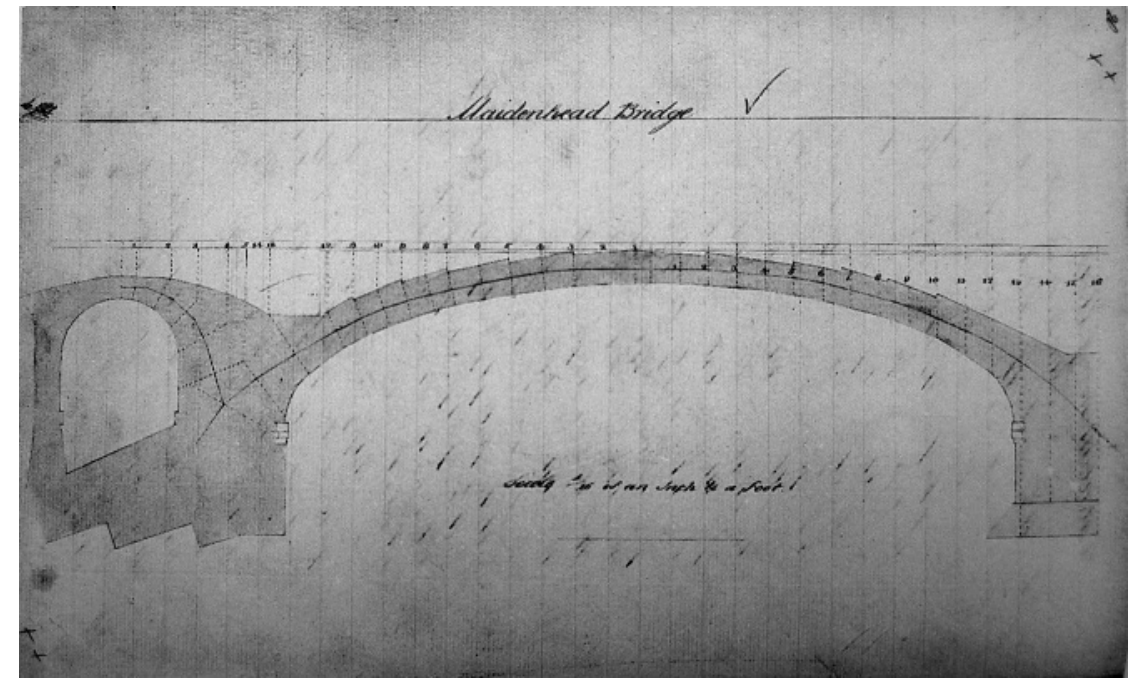

Figure 6. Brunel's thrust line calculation for Maidenhead Bridge showing thrust converging in a single arbitrary block

Considering the equilibrium of the pier top section (Figure 7), some of the stabilising moment comes from the horizontal displacement of the pier reaction and some from the vertical displacement of the thrust in the right-hand span. These movements are all small compared with the large offset of the live load.

The relationship between live and dead load is also significant. If maximum load vehicles are considered, railway loading now allows $25 \mathrm{t}$ axles in groups spaced approximately $2 \mathrm{~m}, 3 \mathrm{~m}$ and $2 \mathrm{~m}$. This will position a total of $100 \mathrm{t}$ well inside a span of $10 \mathrm{~m}$. A bridge of this scale will have a self-weight of approximately $50 \mathrm{t} / \mathrm{m}$ width per span. If a live load were carried by two spandrel walls $600 \mathrm{~mm}$ thick and $900 \mathrm{~mm}$ apart

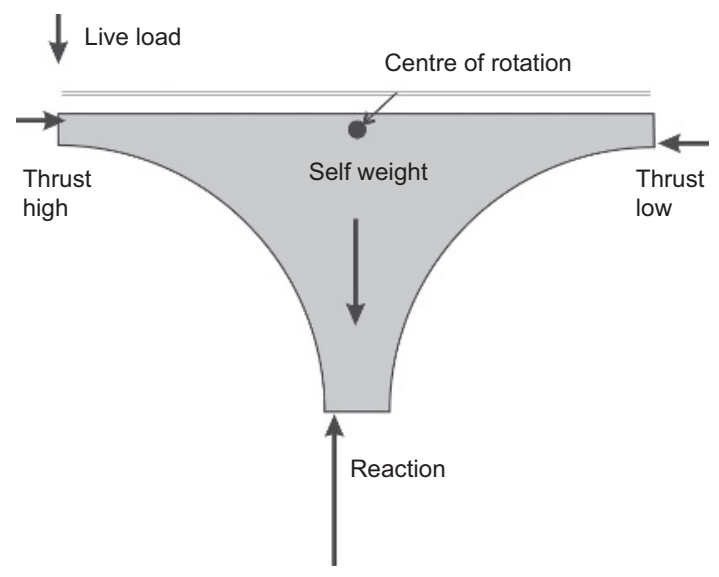

Figure 7. Force balance on pier head that would allow a total spread of just over $2 \mathrm{~m}$ so the live load and dead load are approximately equal without allowing for any dynamic effects.

Because the pier top block, whether it contains voids or not, is a continuum rather than an arch rib, it can be considered as a rigid piece. The horizontal stiffness of the system at arch crown level is very large compared with that of the pier top, so there will be a tendency for this block to rotate about a point near the centre of the pier and close to the level of the extrados of the arch crown. In other words, the rotations required to move the forces will involve a horizontal translation at the top of the pier causing a widening of the loaded span and a shortening of the unloaded span, exactly as modelled in the 1991 paper (Harvey and Smith, 1991).

The rotations are shown in Figure 8. The rotation will be very small but one result will be a lever action between the stress points at the arch crowns, which will cause an increase in thrust to help with the stabilising action.

In order to progress further with the understanding of damage, it is necessary to turn to the cross-section view of the structure. This is perhaps best illustrated in the damaged section of the London Road Viaduct in Brighton following bomb damage in 1941 (Figure 2). In this view, it seems that the live loads are likely to be concentrated on the inside spandrel walls and that there will be little distribution between these walls and the outer spandrels. What is more, the outer spandrels continue upwards to form parapets, or at least retaining walls for the ballast. This means that the outer spandrels will be much stiffer than the inner and that they will have no directly applied 
Stiffness and damage in

masonry bridges

Harvey

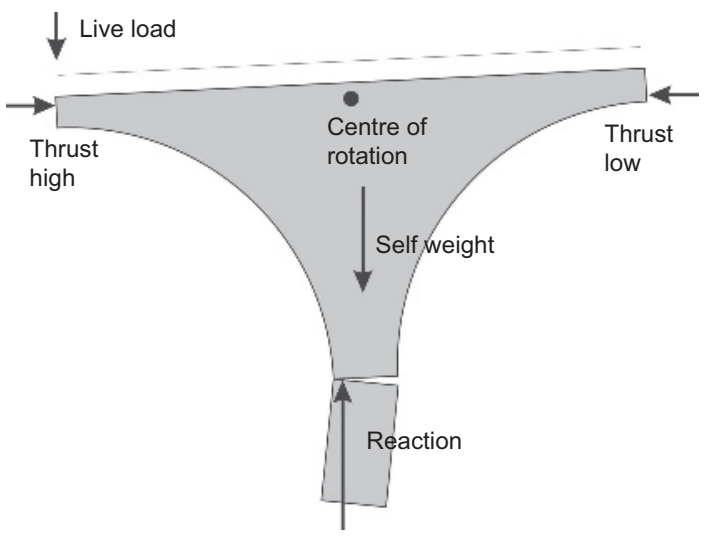

Figure 8. Rocking of the pier head block

disturbing force. As shown in Figure 9, the stabilising thrust is likely to move up into the parapet wall. If the disturbing forces are large, one of two things must then happen. The outer spandrel may rotate much less than the inner and a substantial crack would then develop in the arch. Alternatively, a horizontal crack may develop at the arch crown extrados level and the parapet span across while the outer spandrel rotates with the inner. Both these forms of damage have been witnessed by the author in a single viaduct, as discussed below. The distinction between these two behaviours will depend largely on the stiffness and strength of the torsion box formed by the two half arches and the jack arch or slabbed top of the void (Figure 5). If that is sufficiently stiff, the rotation of the inner spandrel will be resisted but the outer block may rotate with enough force to split off the upper part of the spandrel wall or parapet and so rotate below it (Figure 10). This is the action causing the loosened bricks in Figure 11.

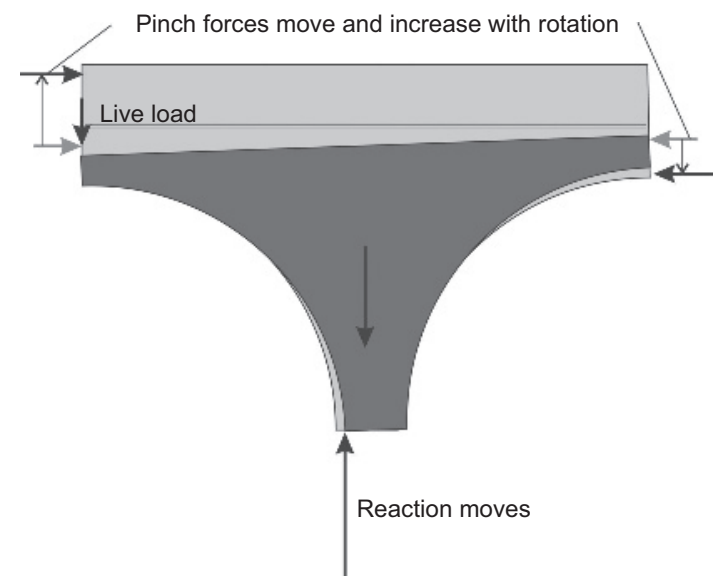

Figure 9. Stabilising forces in outer spandrel

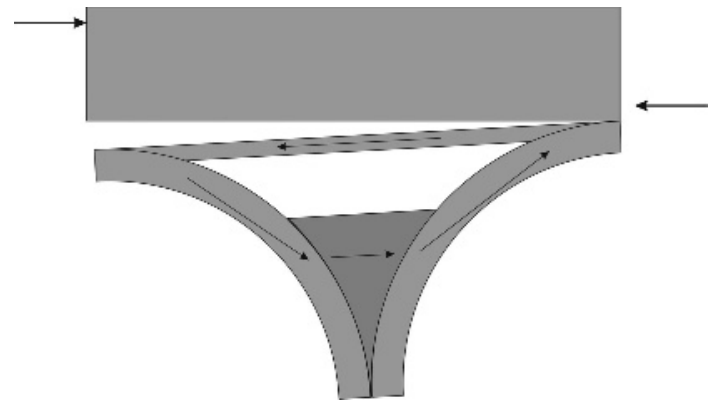

Figure 10. Parapet arching causing a horizontal crack

The bridge shown in Figure 12 has slabbed covers to the spandrel voids and the voids do not link back to the arch but pass over the crown. It is therefore possible for the slabs to be loosened by traffic and the torsion box effectively destroyed. In this circumstance, the inner spandrels may be expected to rotate independently under load while the outer spandrel remains still. The high shear stresses thus developed in the arch will cause cracking. Once the crack has formed, it will articulate and chock stone action (one broken piece jammed in the crack rotates and opens the crack allowing another to fall into place and take over as the movement returns) will progressively jack it open as described in Harvey (1995). This is what seems to have happened in Figure 12.

In a brick arch, an alternative action is possible in which the arch does not crack through vertically, but the lower courses deflect with the inner spandrels while the upper remain attached to the outer. This results in the appearance of ring separation as in Figure 13. Careful measurement with a Moiré Tell Tale (Bill Harvey Associates Ltd., 2012) showed that the crack visible here opened and closed radially without tangential movement, thus

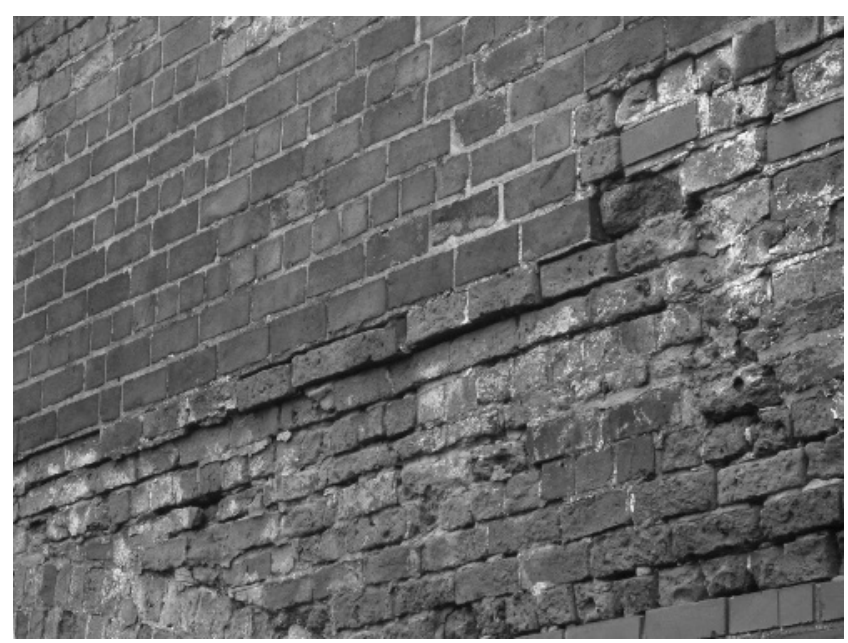

Figure 11. Horizontal crack and loose stones below parapet 


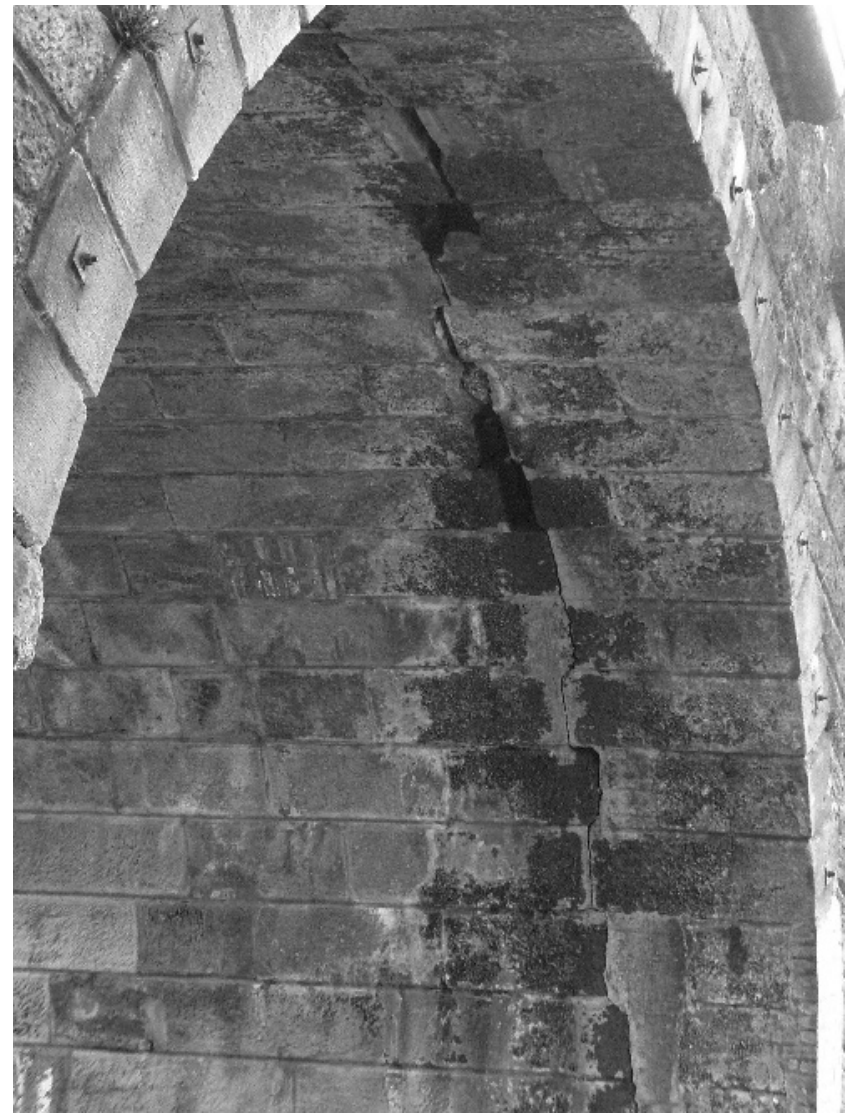

Figure 12. Spandrel crack in arch with internal spandrels

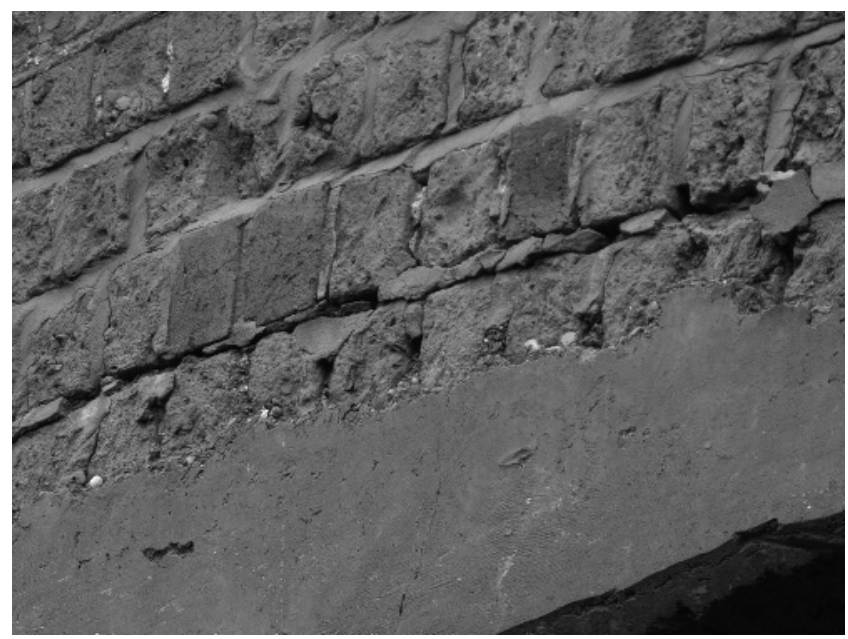

Figure 13. Apparent ring separation four rings down from the extrados

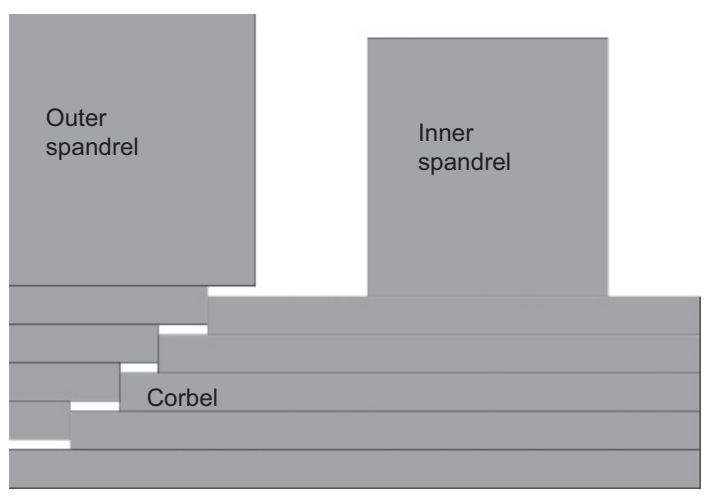

Figure 14. Corbelling action in a brick arch

demonstrating that it was not true ring separation. Cores taken from the edge and from the intrados showed the crack to step up to reach the extrados approximately $700 \mathrm{~mm}$ from the edge. The corbelling action is illustrated in Figure 14.

Such damage as this can only occur under small live loads if the bridge itself is small and flat. Figure 15 shows a small road bridge in which movement of the corbel has caused the release of chock stones that have then destroyed the corbelling parts.

\section{Behaviour of arch viaducts: prognosis}

Having developed an explanation of the behaviour, it is pertinent to consider development of such damage in heavily loaded bridges.

In bridges that appear to be sound, consideration must be given to the likely outcome of any increase in frequency of

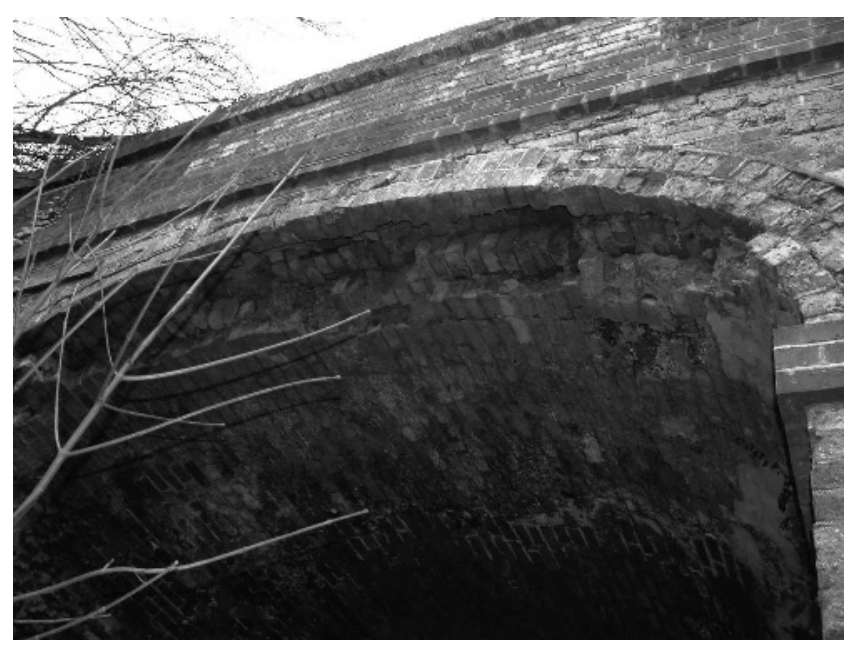

Figure 15. Corbelling followed by disintegration of arch ring in a small road bridge 
heavy loads. For this to be effective, new forms of analysis will be needed.

Where damage has already developed, there is the question of whether it has reduced either the capacity or the life of the structure. Any physical movement of this sort will certainly have consequences. In a spandrel crack, chock stone action will slowly jack the whole arch apart and probably take the outer spandrel wall with it. This will increase the span of the slab or jack arch covering the void. A jack arch will then crack and generate increasing thrust while a slab may slip off its bearing. In both cases, the cover system might become unstable and ballast and fill will then flow into the void generating considerably higher disturbing forces.

The articulation of the arch itself has, in some cases, caused loosening and loss of bricks from the ring (Figure 16).

The capacity of the bridge is not significantly reduced in the short term, but progressive deterioration will lead to such loss and the life of the bridge is thus reduced.

\section{Potential for repair}

Once articulation of the type described has begun, arresting it is likely to be difficult. If the ring has cracked, any attempt to reconnect it is almost certainly doomed to failure. The problem is one of stiffness, not of strength. Unless the repair is stiff enough to ensure the arch (and the spandrel walls above) behave as a unit, the articulation will continue and inevitably cause further damage. One approach might be deliberately to increase the flexibility between the outer and inner spandrels so that they can rotate independently without generating chock stone actions. This would require making a deliberate cut in the arch. The only viable alternative is to reduce the stiffness of the

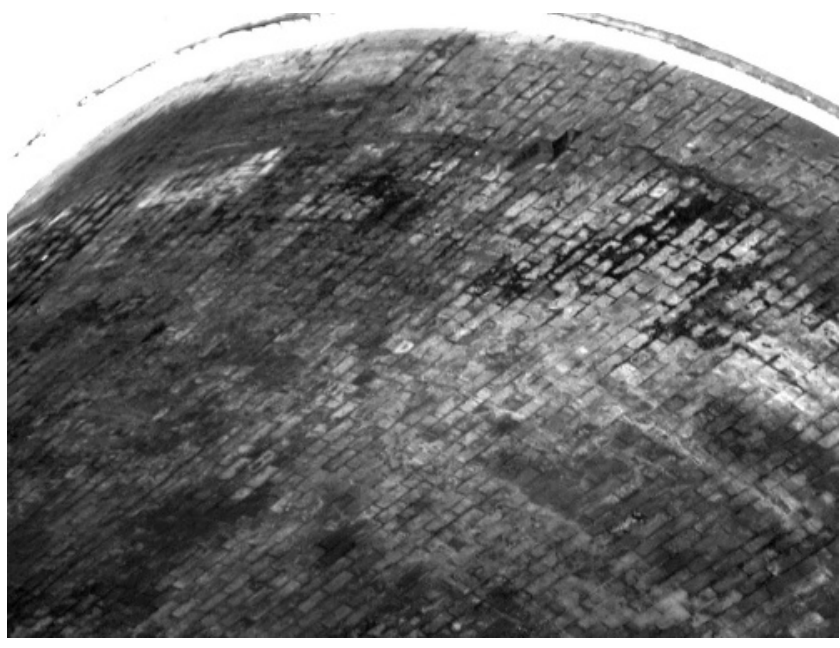

Figure 16. Loosened bricks caused by articulation of the arch outer spandrel wall and re-establish a strong torsion box. Reducing the stiffness of the outer spandrel would require the removal of the parapet and replacement with something less rigid, or at least without a longitudinal shear connection to the spandrel. Creating the box requires restoring full continuity in the arches and the void covers and, where there is none, creating a connection between the arch and the slab near the arch crown.

What would be very difficult is to create an effective repair while traffic is running.

\section{Similar effects in small bridges}

Load damage to small bridges has been discussed previously by Harvey (2006). In that paper, it was suggested that assessment tools produce optimistic results for such bridges as a result of an inappropriate model for distribution. It remains the case that the current distribution model is deeply flawed, but it is also the case that the damage to these small bridges is actually related to the viaduct problems discussed above. Figure 17 shows a typical small bridge and Figure 18 shows the load induced damage to a similar arch. Figure 19 shows internal spandrel walls in another similar bridge that has subsequently had a slab added. These bridges were designed with very shallow fill so that the sleepers were effectively supported directly off the internal spandrel walls. Some of them have since had substantial amounts of ballast or fill added, retained as in Figure 19 with extended brick parapet/retaining walls. Only bridges with shallow fill have suffered serious damage. A strip of arch and two internal spandrel walls are cracked free on the approach side. In most cases, the cracks on the retreating side spread diagonally following the beds and perpends while those on the approach follow the edge of the internal spandrels.

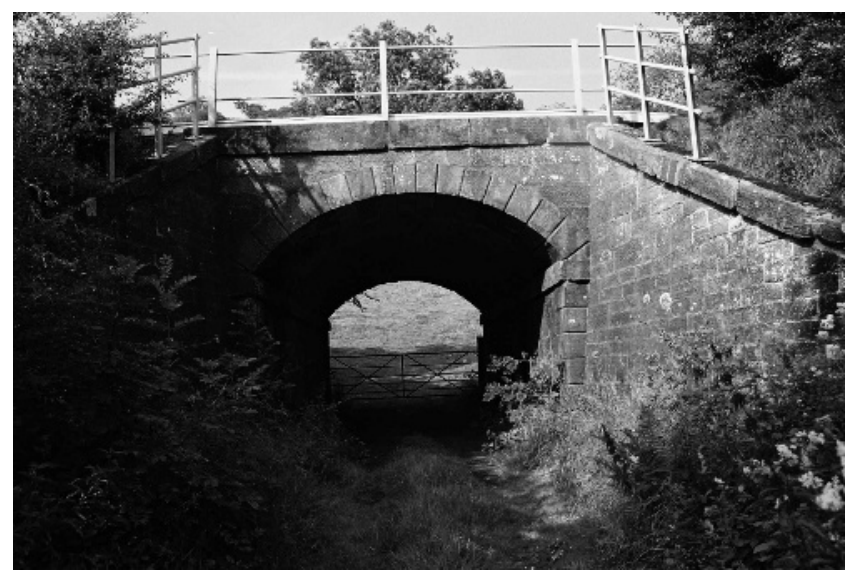

Figure 17. Small bridge suffering from arch ring damage 


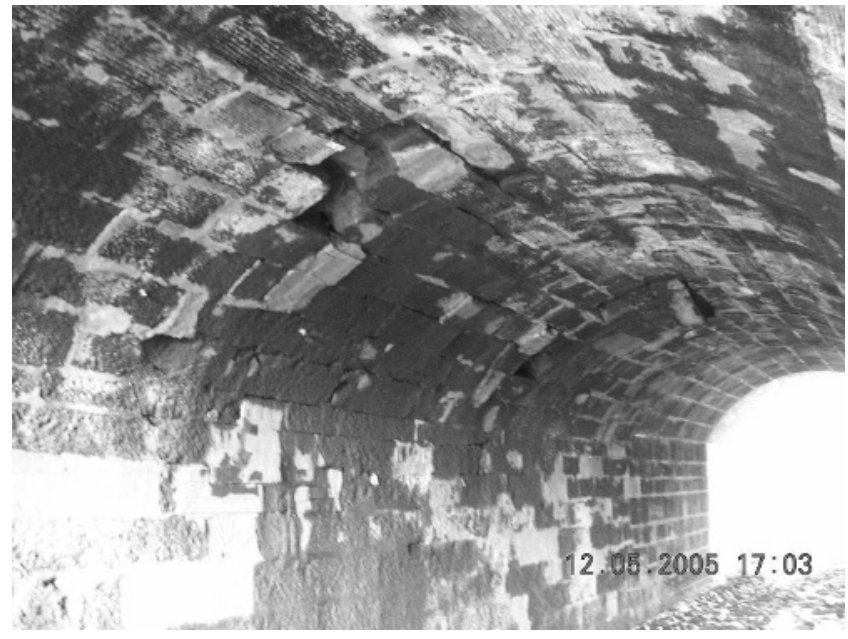

Figure 18. Traffic damage to a small bridge

The concentration of load in this narrow strip, and the very stiff but independent behaviour of the loaded strip and the outer spandrel walls, results in longitudinal splitting of the arch

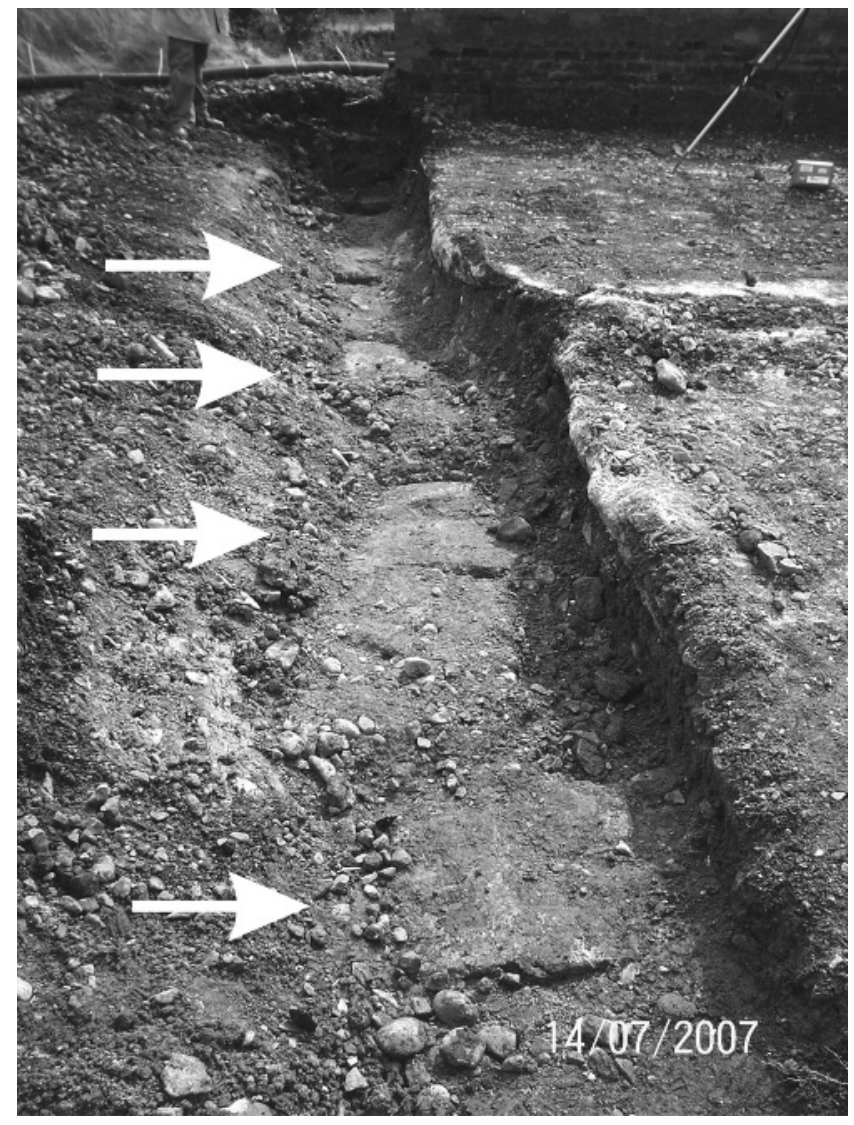

Figure 19. Internal spandrels in a small bridge at the edge of the loaded strip and substantial articulation of the arch itself. Because the arch is made of dressed stone voussoirs, these remain held in place by wedge action even as they drop, but the stones eventually split across at the hard junction and then begin to break up.

\section{Prognosis for small bridges}

In these smaller bridges it must be anticipated that break-up of the voussoirs will lead eventually to more substantial damage and at least partial collapse. It seems that deterioration is most rapid in bridges with fill of $0.5 \mathrm{~m}$ or less. With more than $1 \mathrm{~m}$ of fill the arches show no sign of damage, yet between these depths modest damage and some crack movement can be found. The rate of propagation of damage is thus fill dependent and it seems likely that there will be a depth of fill at which no damage will occur. One compounding factor is that deeper fill necessarily requires higher parapets and thus increased edge stiffness of the arch. It is proposed that, for safety, the depth of fill must be sufficient to ensure that the differential depth over the walls and the arch is small and therefore some lateral distribution of load will occur between the track and the structure.

\section{Treatment of smaller bridges}

The behaviour decribed above implies that attempts to cure the problem by slabbing or saddling the arch will only exacerbate it by creating stiffer load paths. The walls must be removed or cushioned in some way so that differential stiffness can be reduced.

\section{Conclusions}

A mechanism has been described whereby spandrel cracks can be produced in arches below the void between internal spandrel walls and the outer wall. This action does not depend on lateral pressure. Other forms of damage, including horizontal cracks in the spandrels and apparent ring separation, are also linked to the same basic behaviour.

In small bridges with shallow fill, the presence of internal spandrel walls can be the root cause of severe damage. A mechanism by which such damage occurs has been proposed.

The failure processes of arches with soil fill and those with internal spandrel walls of any sort are substantially different. No simple analytical behaviour can hope to represent the behaviour of both types.

\section{9. $\quad$ Further work}

Conclusive diagnosis of the behaviour described will require careful measurement of movement within damaged and undamaged arches in which the construction can be effectively identified. The following measurements are proposed: 
- On several viaducts of different construction, simultaneous measurement of deflection under traffic across the width of adjacent spans coupled with (where possible) measurement of horizontal movement of the pier top.

- In viaducts in which there is a spandrel crack, measurement of displacements at both sides of the crack and at both sides of a pier coupled with measurement of crack width.

- In viaducts with apparent ring separation, measurement of movement at points across the width of the arch in association with movement of the spandrel wall on the same line.

In viaducts with horizontal cracks as in Figure 11, measurement of movement in the crack coupled with that of the arch across the width at the same point.

\section{REFERENCES}

Bill Harvey Associates Ltd. (2012) Moire Tell Tales. See http:// www.moiretelltales.com (accessed 07/06/2012).

Harvey WJ and Smith FW (1991) The behaviour and assessment of multispan arches. The Structural Engineer 69(24): 411417.

Harvey WJ (1995) The origin and treatment of longitudinal cracks in masonry arches. The Structural Engineer 73(23): 411-412.

Harvey WJ (2006) Some problems with arch bridge assessment and potential solutions. The Structural Engineer 84(3): 45 50 .

Harvey WJ and Juhasz Z (2011) Archie-M 1999-2011. See http:// www.obvis.com (accessed 24/04/2012).

\section{WHAT DO YOU THINK?}

To discuss this paper, please email up to 500 words to the editor at journals@ice.org.uk. Your contribution will be forwarded to the author(s) for a reply and, if considered appropriate by the editorial panel, will be published as discussion in a future issue of the journal.

Proceedings journals rely entirely on contributions sent in by civil engineering professionals, academics and students. Papers should be 2000-5000 words long (briefing papers should be 1000-2000 words long), with adequate illustrations and references. You can submit your paper online via www.icevirtuallibrary.com/content/journals, where you will also find detailed author guidelines. 